\title{
Is the modern silica cycle in isotopic mass balance?
}

\author{
ELIZABETH TROWER ${ }^{1}$ AND SHAILY RAHMAN ${ }^{2}$
}

${ }^{1}$ University of Colorado Boulder

${ }^{2}$ University of Southern Mississippi, University of Colorado

Boulder

Presenting Author: lizzy.trower@colorado.edu

Stable silicon isotope compositions $\left(\delta^{30} \mathrm{Si}\right)$ of geological reservoirs have increasingly been applied as proxies for reconstructing shifts in the past silica cycle. Many of these applications rely explicitly or implicitly on the assumption that the surface Earth Si isotope budget is in mass balance with bulk silicate Earth (BSE), such that trends in $\delta^{30} \mathrm{Si}$ over time can be attributed to changes in flux from key silica reservoirs. We assembled a compilation of $\delta^{30} \mathrm{Si}$ data from modern siliceous materials representing the major sources and sinks of reactive silica across marine and terrestrial systems, to which we applied an inverse model to test common assumptions with respect to isotope mass balance. The $\delta^{30} \mathrm{Si}$ compositions of authigenic clay minerals formed through reverse weathering are poorly constrained, so we used our model to estimate the distribution of $\delta^{30} \mathrm{Si}$ values in this sink. Model results demonstrated that the distribution of reverse weathering $\delta^{30} \mathrm{Si}$ values closely match the distribution of diatom $\delta^{30} \mathrm{Si}$ values, conflicting with the previous assumption that these clays would be offset from the modern $\delta^{30} \mathrm{Si}$ diatom values, or, in the Precambrian, primary abiotic chert, by several permil. To reconcile our results with experimental laboratory studies, we suggest $\delta^{30} \mathrm{Si}$ fractionation between diatoms and reverse weathering products in the modern ocean could be modeled as a closed system (i.e., Rayleigh distillation) or that $\mathrm{Si}$ isotope re-equilibration is an important process. Model results also revealed $\sim 10-20 \mathrm{Tmol} / \mathrm{yr}$ Si released during silicate mineral weathering are stored in continental silica sinks as pedogenic clay minerals, phytoliths, and freshwater diatoms. This translates to a global 2:1 Si:C molar ratio of silicate weathering products, consistent with common assumptions of incongruent weathering reactions. In summary, our model results show the modern surface Earth $\delta^{30} \mathrm{Si}$ budget is in mass balance with BSE, reverse weathering does not impart a distinct $\delta^{30} \mathrm{Si}$ signature from diatoms, and incongruent silicate mineral weathering best describes silicic acid production via atmospheric $\mathrm{CO}_{2}$ consumption on a global scale. 